\title{
ANÁLISE DO DISCURSO DO OUTRO EM TEXTOS ACADÊMICOS QUE VERSAM SOBRE A EDUCAÇÃO AMBIENTAL
}

\section{ANALYSIS OF THE OTHER'S SPEECH IN ACADEMIC TEXTS DEALING ON ENVIRONMENTAL EDUCATION}

\author{
Natália Penitente Andrade* \\ Fernanda do Rocio Portela** \\ Mariana Mativi**
}

\begin{abstract}
RESUMO: O objetivo geral é descrever os mecanismos textuais utilizados na incorporação e analisar seus efeitos de sentido. Além disso, tencionamos contribuir com os processos de produção de conhecimento do campo da educação ambiental identificando e classificando diferentes modos de apropriação indevida com auxílio da perspectiva de discurso do Outro de Bakhtin (2002). Como aspecto metodológico, selecionamos textos acadêmicos de universidades públicas do período de 2012 a 2019 , por meio das palavras-chave: sustentabilidade, desenvolvimento sustentável, Rio + 20 . Como aparato teórico mobilizamos as concepções de Bakhtin (2002), Puh (2018), ao realizar uma análise de texto acadêmico na intenção de analisar o modo como o pesquisador se apropria do discurso do outro em um trabalho científico, com base em categorias taxonômicas de Cabe (2003), e as concepções teóricas de Pottier (1978). Verificamos que, por meio dos mecanismos linguísticos, a ação sobre a leitura dos conceitos teóricos é negada pelo pesquisador, bem como notamos que o pesquisador assume a condição que somente legitima o texto que lê, isentando-se de participar da reconstrução dos sentidos. Outro aspecto a ser destacado é a quantidade de textos copiados, as próprias ideias e o discurso estabelecido são distorcidos nas apropriações para tentar apresentar uma individualidade no que se propõe propagar.
\end{abstract}

Palavras-chave: Texto acadêmico. Educação ambiental. Análise do Discurso.

ABSTRACT: The general objective is to describe the textual mechanisms used in the incorporation of discourses and to analyze their effects of meaning in the text. In addition, we intend to contribute to the processes of knowledge production in the field of environmental education by identifying and classifying different modes of misappropriation with the help of Bakhtin's (2002) perspective of the Other's discourse. As a methodological aspect, we selected academic texts from public universities from 2012 to 2019, using the keywords: sustainability, sustainable development, Rio +20 . As a theoretical apparatus we mobilized the conceptions of Bakhtin (2002), Puh (2018), by performing an analysis of academic texts with the intention of analyzing how the researcher appropriates the discourse of the other in a scientific work, based on

* Universidade de São Paulo (USP). Contato: nataliapenitente@usp.br

** Universidade de São Paulo (USP). Contato: ferp25@usp.br

*** Universidade de São Paulo (USP). Contato: mariana.mativi@usp.br 
taxonomic categories by Cabe (2003), and the theoretical conceptions of Pottier (1978). We verified that, through linguistic mechanisms, the action on the reading of theoretical concepts is denied by the researcher, and we note that the researcher assumes the condition that only legitimizes the text he reads, exempting himself from participating in the reconstruction of meanings. Another aspect to be highlighted is the amount of copied texts, the ideas themselves and the established discourse are distorted in the appropriations in an attempt to present an individuality in what it proposes to propagate.

Keywords: Academic text. Environmental education. Speech analysis.

\section{INTRODUÇÃO}

Este texto é resultado de uma pesquisa maior ${ }^{1}$ que visa analisar os sentidos em relação ao papel de elementos centrais da dimensão política de Educação Ambiental², como cidadania, emancipação, empoderamento, democracia, participação, entre outros. Essa pesquisa usa a plataforma de dados $\mathrm{EArte}^{3}$, que disponibiliza teses e dissertações de educação ambiental de todas as universidades brasileiras. Para tanto, o grupo de pesquisa desenvolveu linhas de estudo para aprofundar a análise do discurso desses textos acadêmicos que versam sobre educação ambiental.

No entanto, o presente projeto tem como questão norteadora: Podemos construir, a partir das análises de dissertações e teses em educação ambiental constantes do Banco EArte, quais aspectos da dimensão têm sido mais explorados pelos pesquisadores? Dessa forma, tencionamos discutir esses aspectos a partir do levantamento dos textos acadêmicos, bem como abordando a frente de discussão desses trabalhos.

Ao realizar um levantamento dos textos acadêmicos, verificamos uma recorrência de dissertações e teses atreladas ao ensino sustentável, trabalhos relacionados à educação ou políticas de sustentabilidade voltadas à escola. Também, se refere às discussões sobre desenvolvimento sustentável, bem

\footnotetext{
1 Intitulado: "Configurações da dimensão política no discurso materializado em dissertações e teses de Educação Ambiental", coordenado pelo professor Dr. Valdir Heitor Barzotto.

2 Chamada Universal CNPq Processo: 437408/2018-3 - Coordenação Prof. Dr. Valdir Heitor Barzotto.

3 Banco de dados de Teses e Dissertações sobre Educação Ambiental; Disponível em: http://www.earte.net/teses/ Acesso em: 25 out. 2021.
} 
como temas relacionados à crise do meio ambiente e perspectiva de atividades voltadas para ações sustentáveis.

Para o levantamento do corpus, selecionamos textos acadêmicos de universidades públicas do período de 2012 a 2019, por meio das palavras-chave: sustentabilidade, desenvolvimento sustentável, Rio + 20. Como aparato teórico mobilizamos as concepções de Bakhtin (2002) sobre o discurso direto e indireto e o conceito de dialogismo, bem como as proposições sobre o discurso de outrem. Também recorremos a um procedimento semelhante por Puh (2018) ao realizar uma análise de texto acadêmico na intenção de analisar o modo como o pesquisador se apropria do discurso do outro em um trabalho científico, com base em categorias taxonômicas de Cabe (2003), e as concepções teóricas de Pottier (1978) sobre modalização linguística, em que, esta, refere-se à marca do enunciador ao expressar um julgamento do falante perante a proposição.

Com isso, encontramos o total de sete pesquisas, do nosso levantamento, em que elas apresentam uma concepção fundamentada em decorrência do debate da ciência, tecnologia e sociedade. Além disso, notamos que, nessas pesquisas, está presente a ideia de que a educação sustentável contribui para a formação de professor e é moldada pelo caráter deôntico marcado pelos verbos modais: dever, poder, ou pelas expressões: é preciso, é necessário, esse modo do sujeito expressar-se na escrita constrói um indício de um tom prescritivo que orienta os objetos de pesquisa desses trabalhos.

A partir disso, entendemos que há uma consistência de um valor apreciativo nos excertos, e este tom, conforme Araújo (2016) desenvolve em sua tese, dá margem para que a pesquisa seja um veículo de promoção do objeto discursivo - nos casos analisados - desenvolvimento sustentável, crise ambiental e os discursos da (UNESCO). E, contudo, temos como hipótese de pesquisa que há uma influência do discurso publicitário na elaboração de textos acadêmicos, pois, no que se refere à especificidade do discurso, no caso da sustentabilidade, cabe dizer que ele não é marcado no modelo de texto, ou seja, não tem a estrutura e as marcas linguísticas próprias do texto publicitário, mas apresenta a mesma lógica de interlocução, o mesmo jogo de imagens com o enunciatário - compreendendo-o também como consumidor. 
Considerando essa hipótese, temos como objetivo geral descrever os mecanismos textuais utilizados na incorporação e analisar seus efeitos de sentido, além disso tencionamos contribuir para a melhoria dos processos de produção de conhecimento do campo da educação ambiental identificando e classificando diferentes modos de apropriação indevida do discurso do Outro Bakhtin (2002), passando por procedimentos de apropriação textuais e discursivos.

\section{APARATO TEÓRICO}

Para Bakhtin, o discurso citado é o discurso no/sobre o discurso, e, ao mesmo tempo, uma enunciação sobre outra entendemos que o discurso citado é compreendido pelo falante como a enunciação de uma outra pessoa, de forma que "O "discurso alheio" é o discurso dentro do discurso, o enunciado dentro do enunciado, mas ao mesmo tempo é também um discurso sobre o discurso, o enunciado sobre o enunciado" (BAKHTIN, 2002, p. 249).

Dessa forma, o discurso de outrem constitui mais do que o tema no discurso; ele pode entrar no discurso e na sua construção sintática. Portanto, o discurso citado conserva sua autonomia estrutural e semântica sem alterar o sentido semântico da enunciação citada.

Para pensar quando se usa o discurso alheio: o mecanismo desse processo, ou seja, o uso do discurso do Outro, não se trata de uma situação individual, mas social, pois ao utilizar o discurso do outro seleciona elementos sintáticos ou de sentido da enunciação de outrem que são socialmente pertinentes e constantes, e por consequência, transmite de maneira reduzida a uma dada comunidade linguística. Dessa forma, o autor denota diferenças entre: recepção ativa da enunciação de outrem e sua transmissão no interior de um contexto em que,

A inter-relação entre o discurso transmitido ("alheio") e o discurso transmissor ("autoral") são, segundo o autor, o verdadeiro objeto de estudo, pois a partir desta relação está refletida a orientação social e ideológica envolvida na comunicação. Nesta transmissão há a definição de um "estilo linear" ou "estilo pictórico". Na primeira, há uma delimitação mais 
clara e estabelecida entre as fronteiras do discurso alheio e o autoral, enquanto na segunda esta fronteira ocorre de maneira mais sutil e flexível. Este estilo de dinâmica apresentada se relaciona com a utilização de discurso direto ou indireto, por exemplo. (BAKHTIN, 2002, p. 254).

Contudo, o jogo de transmissão do discurso do outro leva em conta uma terceira pessoa - a pessoa a quem está sendo transmitidas as enunciações citadas e essa informação para uma terceira pessoa é de primordial importância. Toda essência da apreensão apreciativa da enunciação de outrem, tudo o que pode ser ideologicamente significativo tem sua expressão no discurso de interior.

Com essa dupla relação no jogo enunciativo, Bakhtin (2002, p. 148) apresenta como comentário efetivo e réplica interior unem-se, e, consequentemente, isso gera o discurso citado. O que nos chama atenção nessas postulações do pesquisador russo é analisar essas questões pensando no discurso a transmitir e aquele que ser para transmiti-lo. Por esse motivo, quando há a incorporação dessas citações nos textos acadêmicos, a problemática se apresenta na apropriação do discurso do Outro, sem que haja diálogo entre eles.

Essas unidades do discurso interior, que poderiam ser chamadas impressões globais de enunciações, estão ligadas uma à outra, e sucedem-se uma à outra, não segundo as regras da lógica ou da gramática, mas segundo leis de convergência apreciativa (emocional), de concatenação de diálogos e numa estreita dependência das condições históricas da situação social e de todo o curso pragmático da existência. Somente a explicitação das formas que as enunciações completas tomam e, em particular, as formas do discurso dialogado, pode esclarecer as formas do discurso interior e a lógica particular do itinerário que elas seguem na vida interior. (BAKHTIN, 2002, p. 148, grifos do autor).

Ao expressar esse jogo dialógico apresentam tendências, pois, na intenção de conservar o discurso de outrem pode querer conservar a integridade e autenticidade, bem como de tentar manter um 'infiltração' das entonações próprias do autor citado; a isso Bakhtin (2002) chama de estilo linear; na segunda questão essa dinâmica de inter-relação da enunciação do discurso citado a tendência é atenuar os as palavras nítidas do discurso de outrem a voz do autor 
perde-se no fio da enunciação bem como as particularidades da realização verbal.

Pensar sobre a configuração da dimensão política: Deve-se levar em conta que que a posição de um discurso a ser citado ocupa uma hierarquia social de valores, quanto mais forte for o sentimento da enunciação de outrem, mais claramente definidas serão as fronteiras e menos acessível será ela a à penetração exteriores de réplica e comentários

Para fazermos a análise, iremos focar nas subcategorias que incidem objetivamente sobre os procedimentos linguísticos que nos ajudarão a compreender de que modo aplicamos as categorias, para depois, mostrar a existência de critérios que identificamos nas apropriações indevidas.

Abaixo, expomos, uma seleção de categorias taxonômicas de Cabe (2003, p. 2-4) e as respectivas explicações expostas pelo autor:

- $\quad$ Plágio direto: O material de comprimento substantivo é copiado literalmente da fonte, sem atribuição ou uso de aspas.

- Truncamento: O material é copiado literalmente da fonte, com o original abreviado pela exclusão de palavras ou frases iniciais ou finais.

- Excisão: O material é copiado literalmente da fonte com uma ou mais palavras excluídas do meio das frases.

- Inserções: O material é copiado literalmente da fonte com palavras ou frases adicionais (geralmente qualificadores como "muito") inseridas no material da fonte original.

- Reordenação: O material é copiado literalmente da fonte com (a) sentenças em uma ordem diferente, ou (b) palavras ou (c) cláusulas em uma determinada sentença em uma ordem diferente.

- Inversão: O material é copiado literalmente da fonte com a ordem de (a) cláusulas ou (b) palavras na fonte original invertidas.

- Substituição: O material é copiado literalmente da fonte com um sinônimo ou frase substituída por palavras ou frases da fonte original.

- $\quad$ Mudança de tempo ou pessoa ou número: O material é copiado literalmente da fonte, exceto que os tempos verbais foram alterados (por exemplo, do presente para o passado) ou a pessoa dos pronomes foi alterada, por exemplo, da primeira para a terceira pessoa. o sentido da sentença foi alterado de singular para plural.

- Mudança de voz: o material é copiado (essencialmente) literalmente da fonte, com sentenças na voz ativa alteradas para passivo ou vice-versa. 
O autor apresenta outras subcategorias, mas selecionamos algumas para analisar os textos acadêmicos, portanto, essas exposições não se limitam à perspectiva do referido autor, e, deixamos um incentivo para que o leitor busque as demais informações no texto de Cabe (2003). Assim, na seção seguinte deste artigo, apresentamos um quadro de uma análise comparativa entre um trecho de um texto acadêmico e trechos do texto científico fonte em entendemos que houve apropriação indevida no discurso relatado do texto acadêmico em análise.

\section{ASPECTOS METODOLÓGICOS}

Para observarmos os efeitos de sentido dos enunciados, tomaremos as relações semânticas e dialógicas estabelecidas com o conjunto de enunciados encadeados que compõem o texto das produções acadêmicas selecionadas. Para além disso, realizamos um levantamento a partir do mecanismo das palavras-chave de pesquisa disponíveis na plataforma EArte. ${ }^{4}$ Utilizamos como palavras-chave: Sustentabilidade, desenvolvimento sustentável, Rio +20 , com um recorte do período de 2012 a 2019, textos acadêmicos de universidades públicas no total de quatorze textos acadêmicos.

Verificamos que os textos acadêmicos perpassam por discussões sobre a educação e o ambiente escolar, também por formação em educação para o desenvolvimento sustentável. Há textos que vinculam uma crise ambiental na modernidade, ou seja, criam um cenário negativo para então propor postulações possíveis e atestando com os autores mencionados.

O quadro abaixo explicita a composição do nosso corpus.

\begin{tabular}{|c|c|}
\hline \multicolumn{2}{|c|}{ Quadro 1 - Composição do corpus } \\
\hline Gênero acadêmico & Identificação \\
\hline Dissertação & D01 \\
\hline Tese & T02 \\
\hline Dissertação & D03 \\
\hline
\end{tabular}

\footnotetext{
${ }^{4}$ Disponível em: <http://www.earte.net/>. Acesso em: 11 dez. 2019.
} 


\begin{tabular}{|c|c|}
\hline Dissertação & D04 \\
\hline Tese & T05 \\
\hline Tese & T06 \\
\hline Dissertação & D07 \\
\hline Dissertação & D08 \\
\hline Dissertação & D09 \\
\hline Dissertação & D11 \\
\hline Dissertação & D12 \\
\hline Dissertação & D13 \\
\hline Dissertação & D14 \\
\hline
\end{tabular}

Fonte: Autoria própria (2020).

Feito o levantamento, passamos a descrever as discussões realizadas pelos pesquisadores e elencar o recorte para esta análise. Diante dos textos selecionados, notamos que há uma recorrência de circunscrever o desenvolvimento sustentável a uma 'crise do meio ambiente', portanto, ações devem ser feitas para tal, essas ações são destinadas à educação, no ambiente escolar a D01, D02, D04, D07 perpassam essas questões.

Notamos que o procedimento de textualização dos posicionamentos dos pesquisadores transcorre uma construção de um território de uma depreciação no contexto ambiental, quando se diz alinha uma argumentação enumerando vários fatores, tais como significativas transformações históricas, a modernidade ocidental, bem como o apego ao consumismo, também correlaciona essas 'ações' de uso desenfreado das riquezas naturais, a humanidade.

Logo após a construção dessa argumentação em prol da construção de uma estrutura para justificar a pesquisa e a investigação a partir das proposições, iniciamos uma análise destes textos. Desse modo, verificamos por meio do verbo modal epistêmico no futuro do presente (POTTIER, 1978) "educação deverá cultivar a sensibilidade, a solidariedade e a espontaneidade" (p.34), ou que a escola "deverá ser transformada num ambiente capaz de projetar a formação 
integral dos seres humanos e o cuidado com a natureza" (p.35). Essas questões são elencadas pelo pesquisador como justificativas em seus problemas de pesquisa na intenção de construir uma proposta de desenvolvimento sustentável. Portanto, esse modo de construção sintática dá margem para que a pesquisa seja um veículo de promoção do objeto discursivo; notamos que a pergunta de pesquisa tem pouca intenção, bem como a sua relação com a construção do objeto, o que se espera de uma proposta de pesquisa e sua construção argumentativa é o desejo de saber sobre e não a comprovação de um pré-dado.

Em ambas as teses e dissertações, as perguntas de pesquisa são uma verificação da teoria, as respostas estão autorizadas por documento oficial para o desenvolvimento sustentável: A Organização das Nações Unidas para a Educação, a Ciência e a Cultura (UNESCO) ou de medidas e extraídas da Conferência das Nações Unidas sobre Desenvolvimento Sustentável (Rio+20).

$\mathrm{Na}$ tese T06, por exemplo, a pergunta de investigação da tese é uma pergunta importada, no sentido de que é sustentada nos documentos oficiais sobre a importância de uma educação científica para uma sociedade sustentável. Parte-se da hipótese de que exista uma lacuna na formação dos professores da educação básica no que se refere ao desenvolvimento sustentável, o uso da expressão no texto acadêmico: "investigar as contribuições e limitações na formação do profissional de Ciências que atuam na educação básica" (p.9) nos propõe essa percepção.

Após a constatação dos discursos de crise ambiental construído no corpus analisado e da aproximação deles com o discurso publicitário, é possível acrescentar acerca dessas reproduções acerca da reprodução do em alguns trabalhos acadêmicos (BARZOTTO, 2004), pois verificamos que o modo como o pesquisador mobiliza ou elabora uma resenha teórica são para atestar ou confirmar o que o pesquisador está querendo sustentar do que para estabelecer uma discussão a fim de chegar a uma perspectiva que melhor auxilie na análise do objeto pesquisado.

Nestas dissertações com as quais analisamos, há muitas citações diretas e indiretas sequencialmente, por exemplo, o pesquisador menciona uma citação 
direta e logo após menciona De acordo com fulana (2001) a ideia expressa no livro $X$ constitui a base do, isso é exposto em uma parcela parte das teses e dissertações. Há uma recorrência de usos para a autora, de acordo com a autora, o autor acreditou/acredita, para compreensão desse termo é necessário recorrer a; de acordo com a compressão do autor; o autor pontua, ressalta, reflete, dentre outros, notamos essas expressões dissociadas de um posicionamento, ou uma articulação de ideias, há pouca produção escrita do pesquisador. Essas marcas linguísticas são expostas de uma maneira que a voz do pesquisador é apagada, essa postura delineia os modos de relação que cada sujeito estabelece com o conhecimento, ou com a produção de conhecimento.

Essas marcas linguísticas que delineia um processo enunciativo podem ser analisadas a como modos de submissão, identificação, reprodução, filiação (BARZOTTO, 2004), pois ao verificarmos isso, não estamos isentando o fato de que é necessário mobilizar teorias e que o gênero perpassa essa construção, entretanto ao definirmos um objeto, uma teoria e pergunta de pesquisa devemos caminhar na reflexão de que esses autores nos ajudem a produzir o conhecimento e não que façamos um uma 'listagem' dos autores que discutam sobre o tema e ausente uma discussão e confronto entre perspectivas teóricas elencadas. 


\section{DISCURSO DE “OUTREM" NA INCORPORAÇÃO DO DISCURSO CIENTÍFICO: UMA ANÁLISE DISCURSIVA}

Quadro 2 - Análise de mecanismos linguísticos incorporados no texto acadêmico.

\begin{tabular}{|c|c|c|}
\hline Texto acadêmico original & $\begin{array}{l}\text { Procedimento de apropriação } \\
\text { indevida }\end{array}$ & $\begin{array}{l}\text { Texto acadêmico com } \\
\text { apropriação do original }\end{array}$ \\
\hline $\begin{array}{l}\text { Estas determinações } \\
\text { gerais devem ser } \\
\text { completadas não só por } \\
\text { seu ajustamento às } \\
\text { diferentes condições de } \\
\text { desenvolvimento } \\
\text { adaptação do modo de } \\
\text { reprodução ao meio } \\
\text { geográfico e a história } \\
\text { cultural de cada formação } \\
\text { social que dão } \\
\text { especificidade a estas leis } \\
\text { gerais, como efeito de } \\
\text { sua articulação com as } \\
\text { determinações de outras } \\
\text { formações sociais. }\end{array}$ & $\begin{array}{l}\text { Substituição > (estas - essas) } \\
\text { Inserção > (são ajustadas) } \\
\text { Inserção > (assim como) } \\
\text { Substituição > (com efeito - } \\
\text { como consequência) } \\
\text { Plágio direto > (às diferentes } \\
\text { condições de desenvolvimento } \\
\text { e adaptação do modo) } \\
\text { Plágio direto > (história cultural } \\
\text { das diferentes formações } \\
\text { sociais que dão especificidade) } \\
\text { Plágio direto > (as } \\
\text { determinações de outras } \\
\text { formações sociais) }\end{array}$ & 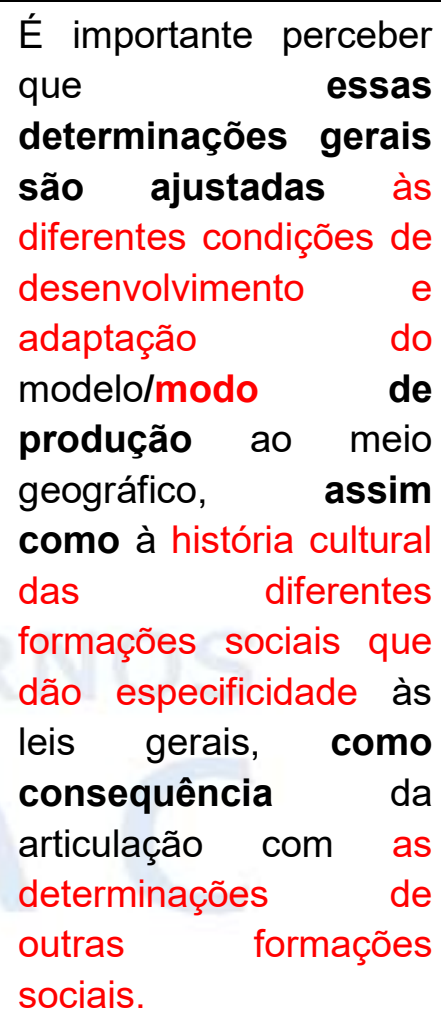 \\
\hline $\begin{array}{l}{[\ldots] \text { entendido como as }} \\
\text { operações adaptativas de } \\
\text { um individuo ou de uma } \\
\text { população biológica a seu } \\
\text { meio ambiente. }\end{array}$ & $\begin{array}{l}\text { Truncamento (frase inteira } \\
\text { copiada, supressão apenas de } \\
\text { uma e a seu) } \\
\text { Substituição > (entendido - } \\
\text { compreendido) }\end{array}$ & $\begin{array}{lr}\text { Este comportamento } \\
\text { social, compreendido } \\
\text { como as operações } \\
\text { adaptativas } & \text { de } \\
\text { indivíduos } & \text { ou de } \\
\text { populações } & \text { biológicas } \\
\text { ao ambiente. } & \end{array}$ \\
\hline $\begin{array}{l}{[\ldots] \text { Os princípios da }} \\
\text { termodinâmica e os } \\
\text { balances de energia têm } \\
\text { sido aplicados no campo } \\
\text { da antropologia, da } \\
\text { ecologia e do social. }\end{array}$ & $\begin{array}{l}\text { Inserções > (muitos) } \\
\text { Substituição > (têm sido - têm } \\
\text { encontrado) } \\
\text { Truncamento > (frase inteira } \\
\text { copiada, inserção apenas de } \\
\text { dois termos) }\end{array}$ & $\begin{array}{l}\text { "A análise dos } \\
\text { processos ecológicos, } \\
\text { sociais e culturais, em } \\
\text { termos de sua } \\
\text { racionalidade } \\
\text { energética, surge da } \\
\text { aplicação a esses } \\
\text { campos, dos princípios } \\
\text { da física, da entropia e } \\
\text { da termodinâmica de } \\
\text { sistemas abertos" }\end{array}$ \\
\hline
\end{tabular}




\begin{tabular}{|c|c|c|}
\hline & & $\begin{array}{l}\text { (LEFF, 2010, p. 53). } \\
\text { Muitos dos princípios } \\
\text { da termodinâmica e os } \\
\text { balanços de energia } \\
\text { têm encontrado } \\
\text { aplicação nos campos } \\
\text { da antropologia, da } \\
\text { ecologia e da sociologia. }\end{array}$ \\
\hline 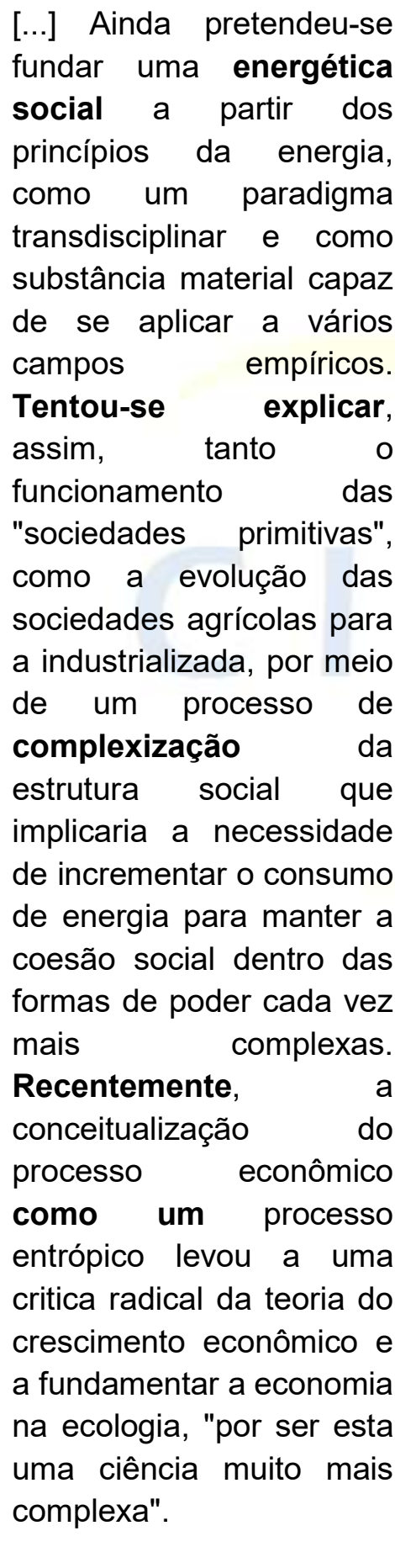 & $\begin{array}{l}\text { Uso inapropriado das aspas > } \\
\text { (energética social) } \\
\text { Inversão > (se aplicar > aplicar- } \\
\text { se) } \\
\text { Inversão > (tentou-se explicar - } \\
\text { houve } \\
\text { tentativas em explicar) } \\
\text { Inserção > (por exemplo) } \\
\text { Substituição > (por meio de - } \\
\text { através de um) } \\
\text { Substituições > (complexização - } \\
\text { complexo de transformação) } \\
\text { Substituição > (como um - como } \\
\text { sendo) } \\
\text { Plágio direto > (todas as partes } \\
\text { que não estão grifadas estão na } \\
\text { íntegra do que o referido autor } \\
\text { diz) }\end{array}$ & 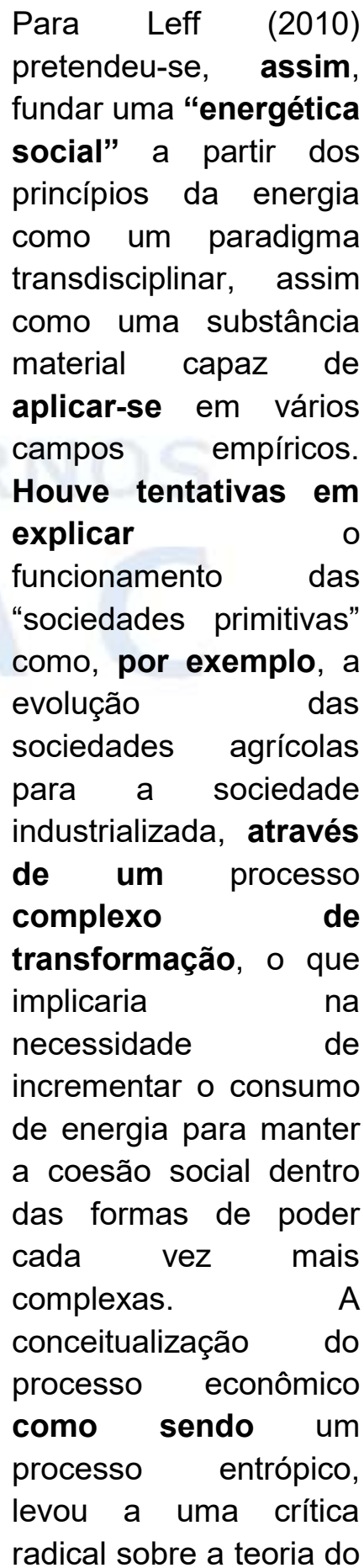 \\
\hline
\end{tabular}




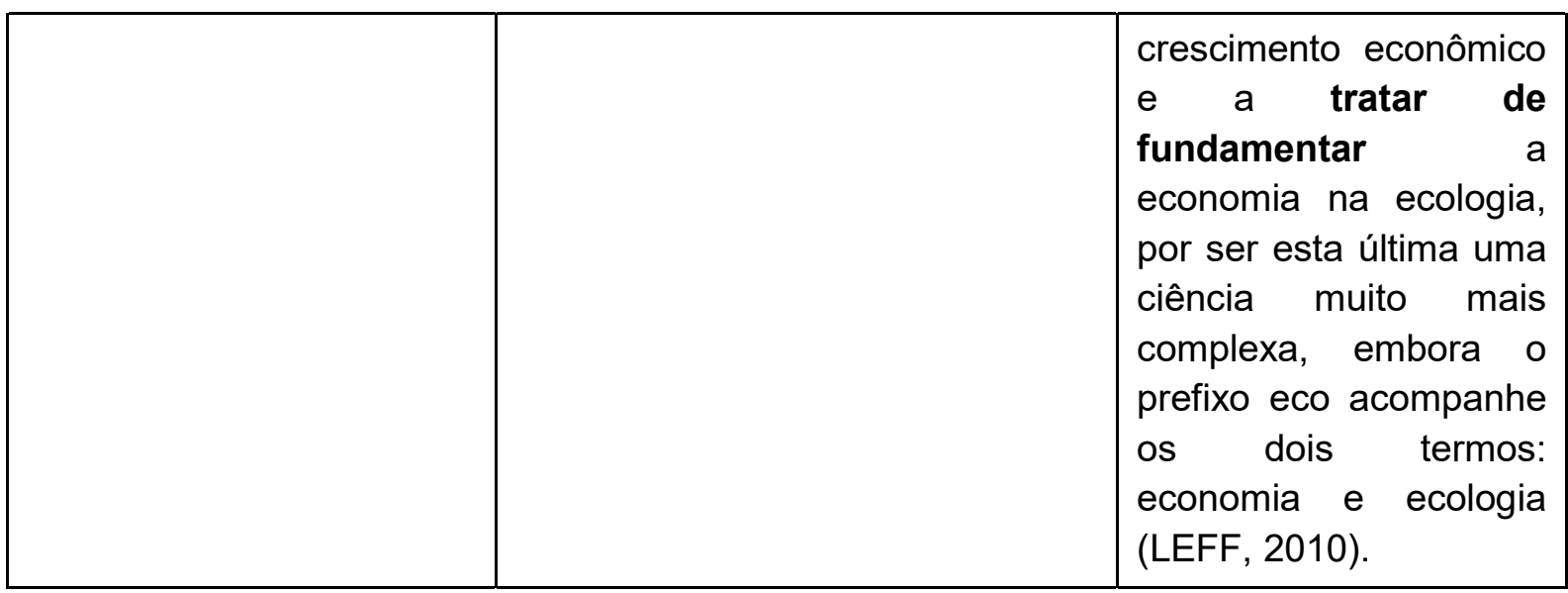

Fonte: Autoria própria (2020).

A intenção não é passar por todos os exemplos nos quais observamos na tese em análise, mas indicar os tipos da apropriação do discurso do Outro, pois compreendemos que as marcações apresentaram o percurso das apropriações e figuram uma série de estado de discussões acerca do que configura enquanto produção de conhecimento, ou conforme Wittgenstein (2000) pontua como a massificação de produção científica.

Questionamos, pois, a repetição dos mesmos elementos textuais, no caso do discurso do referido autor mencionado durante a tese, faz com que o discurso do segundo texto transpareça com uma enunciação de outrem e a cada palavra da enunciação que estamos em processo de compreender, conforme postula Bakhtin (2002) envolve nossas palavras que forma-se uma réplica, e essa compreensão é uma forma de diálogo, ou uma massificação, anulando uma individualidade na produção de conhecimento, ou mobilizando o aparato teórico em prol do que se propõe a discutir. Além disso, essa apropriação reforça que as apropriações indevidas resultam em uma reprodução em massa da discussão sobre o desenvolvimento sustentável. Nesse jogo de vozes, observamos a quantidade de textos copiados, as próprias ideias e o discurso estabelecido são distorcidos nas apropriações para tentar apresentar uma individualidade no que se propõe propagar.

Os verbos marcam as vozes dos autores, mais que isso, ratificam a posição que o pesquisador os confere - como locutores de sua própria pesquisa. O pesquisar transforma a sua leitura sobre o autor citado em uma chave de 
leitura para compreender o conceito citado, a análise do pesquisador transcorre em uma descrição das ações dos autores no texto, ou seja, ao mobilizar os textos teóricos o pesquisador, por meio de discurso direto ou indireto, descreve o que os autores dizem. Isto se relaciona com o que Barzotto (2004) discute em seu artigo A criança falada e a cena de quem a fala que alguns trabalhos acadêmicos, diante de suas análises, ele tem verificado que, mais notadamente no capítulo de resenha teórica e, ademais, em parte do trabalho, os autores citados "[...] são mais úteis para confirmar o que o candidato está querendo sustentar do que para estabelecer uma discussão a fim de chegar a uma perspectiva que melhor auxilie na análise do objeto pesquisado" (BARZOTTO, 2004, p. 3).

Por meio dos mecanismos linguísticos devem ser, compreendido como, 0 autor pontua, dentre outros a ação sobre a leitura dos conceitos teóricos é negada pelo pesquisador, e notamos que o pesquisador assume a condição que somente legitima o texto que lê, isentando-se de participar da reconstrução dos sentidos e de, assumi-la. Araújo (2016) pontua que quando um há uma incorporação discursiva não se trata de produção científica, mas sim vulgarização dos conhecimentos.

Com essas proposições elencadas, o que nos lança neste trabalho é continuar pesquisando a produção escrita acadêmica, bem como a relação do sujeito com a escrita e a produção de conhecimento, conforme expõe Barzotto (2004). Os textos acadêmicos podem ser tomados como dados de pesquisa como um papel duplo, na intenção de analisar o "discurso transmitido" e observar o "discurso que serve para transmitir" (BAKHTIN, 2002), bem como, estabelecer distinções no texto lido entre o que são as estratégias retóricas usadas pelo autor para construir a importância do que está dizendo e o que é conteúdo propriamente dito. As análises desses textos acadêmicos permitem refletir sobre as posições políticas, ideológicas e de dominação que se estabelecem quando determinados discursos sobre língua são propagados. 


\section{CONSIDERAÇÕES FINAIS}

Verificamos que, por meio dos mecanismos linguísticos, a ação sobre a leitura dos conceitos teóricos é negada pelo pesquisador, bem como notamos que o pesquisador assume a condição que somente legitima o texto que lê, isentando-se de participar da reconstrução dos sentidos. Outro aspecto a ser destacado é a quantidade de textos copiados, as próprias ideias e o discurso estabelecido são distorcidos nas apropriações para tentar apresentar uma individualidade no que se propõe propagar.

Em relação à produção de conhecimento, a perspectiva e inserção do pesquisador em seu trabalho enquanto sujeito são essenciais para uma contribuição significativa. Assim, a ausência de uma autoria relevante e de uma reflexão que contribua para essa produção gera como resultado trabalhos que verificam teorias já formalizadas e pouca ou nenhuma nova constatação sobre o corpus analisado. Torna-se, então, uma adequação do corpus ao recorte teórico escolhido inicialmente.

É importante pontuar, como aspecto relevante de dessa análise, que nossas conclusões estão construídas a partir de uma seleção limitada. Apesar disso, a relação entre autor e esses "outros", as teorias e textos que perpassam a produção acadêmica, constitui a base desses resultados. Sendo assim, percebemos uma necessidade de reflexão constante neste processo e uso de discursos de modo que haja um sujeito autor para contribuição da produção de conhecimento.

\section{REFERÊNCIAS}

ARAUJO, Augusto Angelo Nascimento. $\mathbf{O}$ texto acadêmico promocional e a ética do malandro: gestos de análise da incorporação de objetos discursivos em textos. 2016. 241f. Tese (Doutorado em Filologia e Língua Portuguesa) Faculdade de Filosofia, Letras e Ciências Humanas, Universidade de São Paulo, São Paulo, 2016.

BAKHTIN, M. (Volochinov). Marxismo e filosofia da linguagem. 10. ed. Tradução de Michel Lahud et al. São Paulo: Hucitec, 2002. 
BARZOTTO, Valdir Heitor. A criança falada e a cena de quem a fala. In: COLOQUIO DO LEPSI IP/FE-USP, 5., 2004, São Paulo. Proceedings online [...] São Paulo, 2004 . Disponível em: <http://www.proceedings.scielo.br/scielo.php?script=sci_arttext\&pid=MSC00000 $00032004000100012 \&$ Ing=en\&nrm=abn>. Acesso em: 26 mar. 2020.

CABE, P. Taxonomia de procedimentos de plágio. 2003. Disponível em: <http://cms.skidmore.edu/psychology/resources/student/tips.cfm> Acesso em: 20 mar. 2020.

POTTIER. Bernard. Linguística geral: teoria e descrição. Tradução e adaptação portuguesa de Walmírio Macedo. Rio de Janeiro: Presença; Universidade Santa Úrsula, 1978.

PUH, Milan. Apropriação indevida de elaboração alheias nos trabalhos científicos. In: PUH, Milan. Dezescrita. São Paulo: Paulistana, 2018. p. 125-136.

WITTGENSTEIN, Ludwig. Investigações filosóficas. Trad. José Carlos Bruni. São Paulo: Ed. Nova Cultural, 2000. (Col. Os Pensadores). 